\title{
An exceptionally large coronary artery aneurysm in a formerly healthy young woman
}

\author{
B.C. Du Pré · L.W. Van Laake $\cdot$ B.K. Velthuis · \\ E.E.C. de Waal · M.P. Buijsrogge · R.J. Hassink
}

Published online: 8 October 2015

(C) The Author(s) 2015. This article is published with open access at Springerlink.com

A 32-year-old woman presented with progressive dyspnoea for 6 weeks, fatigue, weight loss, chest pain, and night sweats. Apart from an uncomplicated delivery of her third child 4 months ago, she had no medical or family history. Pneumonia was suspected (chest X-ray Supplementary Fig.1a, b), but thoracic computed tomography (CT) was performed to exclude pulmonary emboli.

B.C. Du Pré, L.W. Van Laake contributed equally to this manuscript.

Electronic supplementary material The online version of this article (doi:10.1007/s12471-015-0756-8) contains supplementary material, which is available to authorized users.

\section{R.J. Hassink $(\bowtie) \cdot$ B.C. Du Pré · L.W. Van Laake}

Department of Cardiology, University Medical Center Utrecht, Heidelberglaan 100,

3584 CX Utrecht, The Netherlands

e-mail: r.j.hassink@umcutrecht.nl

\section{B.C. Du Pré}

Department of Medical Physiology,

University Medical Center Utrecht,

Utrecht, The Netherlands

B.K. Velthuis

Department of Radiology, University Medical Center,

Utrecht, The Netherlands

E.E.C. de Waal

Department of Anesthesiology,

University Medical Center Utrecht,

Utrecht, The Netherlands

M.P. Buijsrogge

Department of Cardiothoracic Surgery,

University Medical Center Utrecht,

Utrecht, The Netherlands
The CT surprisingly showed a large intrathoracic mass of $94 \times 80 \mathrm{~mm}$ extending from the sternum to the thoracic spine, compressing the superior and inferior caval veins, the right atrium, and (partly) the right ventricle (Fig. 1, Supplementary Fig. c-e, and Video 1). Further analysis revealed a giant coronary aneurysm (GCA) originating from the proximal right coronary artery (RCA) connecting inferiorly to the distal RCA. Left ventricular function was good (Video 2 and 3). Due to the size and the location of the GCA, surgical exclusion was the treatment of choice (Fig. 2, Supplementary Fig. F). After surgery, the patient recovered well and was discharged on the fifth postoperative day.

GCAs are extremely rare: less than $0.02 \%$ of all cardiac surgery is attributed to GCAs [1]. They are usually related to comorbidities or injuries such as infectious disease, inflammatory disease, trauma, coronary angioplasty, or connective tissue disease but can also occur as a congenital abnormality. [4] It is likely that in the current case, the GCA had existed for many years. Increased workload and hormonal changes during pregnancy and delivery may have contributed to growth and symptoms of the GCA $[2,3]$.

Conflict of interest None declared

Open Access This article is distributed under the terms of the Creative Commons Attribution License which permits any use, distribution, and reproduction in any medium, provided the original author(s) and the source are credited. 


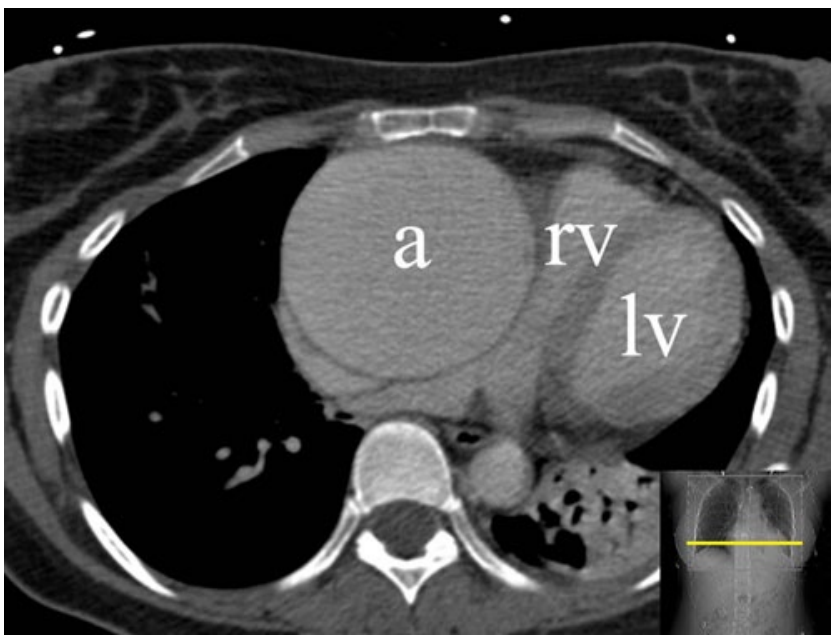

Fig. 1 Thoracic CT showing a large intrathoracic mass. Note the equal densities of the aneurysm and the left ventricular lumen

\section{References}

1. Li D, Wu Q, Sun L, et al. Surgical treatment of giant coronary artery aneurysm. J Thorac Cardiovasc Surg. 2005;130:817-21.

2. Manalo-Estrella $\mathrm{P}$, Barker AE. Histopathologic findings in human aortic media associated with pregnancy. Arch Pathol. 1967;83:336-41.

3. Van Hagen IM, Roos-Hesselink JW. Aorta pathology and pregnancy. Best Pract Res Clin Obstet Gynaecol. 2014;28:537-50.

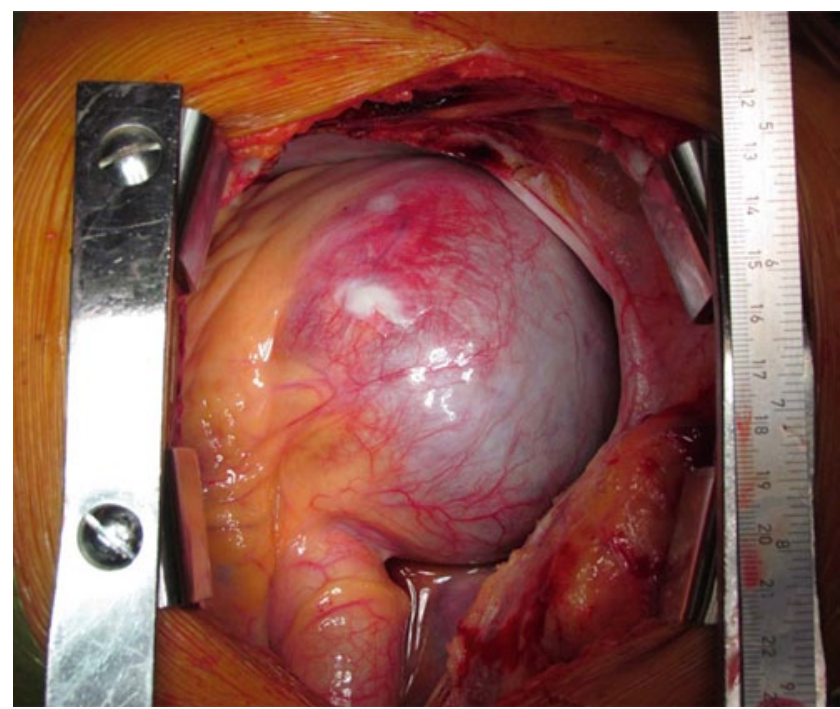

Fig. 2 Giant coronary aneurysm after sternotomy

4. Wal RM van de, Werkum JW van, le Cocq d'Armandville MC, Plokker HW, Morshuis WJ. Giant aneurysm of an aortocoronary venous bypass graft compressing the right ventricle. Neth Heart J. $2007 ; 15: 252-4$. 